\title{
USE OF DEXMEDETOMIDINE AS AN ADJUVANT TO 0.5\% HYPERBARIC BUPIVACAINE IN SUBARACHNOID BLOCK
}

\begin{tabular}{ll}
\hline Anaesthesiology & \\
$\begin{array}{ll}\text { Dr. Dhananjay } \\
\text { Yadav }\end{array}$ & $\begin{array}{l}\text { M.D. Anaesthesia, Senior Resident, Dept. Of Anaesthesia \& Critical Care, S. N. Medical } \\
\text { College, Agra (U.P) }\end{array}$ \\
\hline $\begin{array}{ll}\text { Dr. Suman } \\
\text { Minocha* }\end{array}$ & $\begin{array}{l}\text { M.D. Anaesthesia, Asst. Prof, Dept. Of Anaesthesia \& Critical Care, S. N. Medical } \\
\text { College, Agra (U.P) * Corresponding Author }\end{array}$ \\
\hline $\begin{array}{ll}\text { Dr. Anamika } \\
\text { Mishra }\end{array}$ & $\begin{array}{l}\text { M.D. Anaesthesia, Senior Resident, Dept. Of Anaesthesia \& Critical Care, S. N. Medical } \\
\text { College, Agra (U.P) }\end{array}$ \\
\hline Dr.deepak Joshi & $\begin{array}{l}\text { M.D. Anaesthesia, Asso.prof.., Dept. Of Anaesthesia, R.D.gardi Medical College, Ujjain } \\
\text { (M.P) }\end{array}$ \\
\hline
\end{tabular}

\section{ABSTRACT}

The present study aimed at clinical evalution of dexmedetomidine 10 microgm, as an adjuvant to heavy bupivacaine $0.5 \%$ (4 $\mathrm{ml})$ in subarachnoid block in patients scheduled for lower abdominal surgeries.

Total no. of patients included in the study are 66 who are admitted in orthopaedic ward for lower limb surgeries, who are of ASA grade I \& II and age group between 18-60yrs. All the routine investigations of the patients were done and after complete PAC and preoperative preparations, patients were taken into O.T, all the standard monitoring applied and for subarachnoid block hyperbaric Bupivacaine $0.5 \%$ is a dose of $4 \mathrm{ml}(20 \mathrm{mg}$ ) combined with or without Dexmedetomidine was administrated according to the assigned study group:

1.Group A- Inj. Bupivacaine- 20mg alone- control group

2.Group B- Inj. Bupivacaine- $20 \mathrm{mg}$ with Dexmedetomidine $10 \mathrm{mcg}$-study group

Data on onset \& offset of sensory \& motor block, degree of muscle relaxation, postoperative pain free period were recorded. Dermatome level of block, vitals \& drug related complications were also noted.

On the basis of observations, following conclusions are drawn: Rapid onset \& increased duration of sensory block was seen in Grp B, Onset of motor block \& post operative pain free period was prolonged in Grp. B.

Sedation score was from 0-2 in study group.Other complications in study group were not significant.

\section{KEYWORDS}

Subarachnoid Block, Bupivacaine, Dexmedetomidine, Analgesia.

\section{INTRODUCTION \\ One of the basic reasons to add neuraxial adjuvant drugs with heavy Bupivacaine to subarachnoid block, is to extend postoperative pain relief by prolonging the duration of sensory block. Subarachnoid block is a safe and effective alternative to general anaesthesia when surgical site is located on the lower extremities, perineum and lower abdominal wall. As most of the lower abdominal surgeries are done under subarachnoid block, a neuraxial adjuvant not only prolongs the duration postoperative analgesia but is also effective in attenuating this poorly localizing visceral pain.}

Carl Koller, an ophthalmologist from Vienna has described the use of topical cocaine for the analgesia of eye in 1884. In 1885, the administration of spinal analgesia by Leonard corn, a neurologist in New York for the first time on dog, spinal anaesthesia has progressed since then and is used successfully in number of clinical situations. The first planned spinal anaesthesia for surgery in a man was administered by August bier on 16 august 1898, in Keil, when he injected $3 \mathrm{ml}$ of $0.5 \%$ cocaine solution intrathecally in 34 year old labourer. Since then spinal anaesthesia faced many changes. Many drugs have been used and studied.

With the discovery of Amide local anaesthetic agent, spinal anaesthesia has been revolutionized. They are long lasting and safer drugs. Lignocaine since 1949 had been the main agent but it becomes less popular after reporting of CaudaEquina Syndrome.

Bupivacaine is a well established and most widely used long acting regional anaesthetics, which like all amide anaesthetic have been associated with cardio toxicity when used in high concentration or when accidently, administered IV. The efficiency and tolerability of Bupivacaine for spinal anaesthesia in lower abdominal and lower limb surgery have been demonstrated in several studies. It has shown to produce sufficient surgical anaesthesia and analgesia and consistently shown to reduce side effect profile. Due to its propensity of blocking sensory fiber readily, it serves all purposes for day care surgery. Patient can be mobilized early and discharge sooner.
Dexmedetomidine is selective Alfa 2 adrenoreceptor agonist that modulate antinociception by inhibiting peripheral norepinephrine release thus terminating the propagation of pain signal. At same time post synaptic activation of Alfa 2 adrenoreceptor in the central nervous system inhibit sympathetic activity and may result in hypotension and bradycardia. On the basis of past clinical studies it was observed that Intrathecal dexmedetomidine $10 \mathrm{mcg}$ with bupivacaine do not causes major hemodynamic changes and is a safe adjuvant for post operative analgesia along with bupivacaine.

In view of pharmacological properties of dexmedetomidine, a clinical study was planned with an aim to compare the post operative analgesic and sedative effect of dexmedetomidine used in subarachnoid block as an adjuvant to bupivacaine in patients undergoing lower abdominal surgeries.

\section{MATERIAL \& METHODS}

The present study carried out in the department of anaesthesia after approval from the ethics committee of college and Hospital, on 66 Patients admitted in orthopaedic ward undergoing surgery on lower limb under spinal anaesthesia.

During preoperative visit, each patient was subject to detailed physical and systematic examination to record vital signs, and to rule out any general or local diseases or deformity of spine. The relevant history regarding previous illness was obtained and recorded.

Each patient was investigated under:-

- Complete Urine examination.

- Haemoglobin estimation and complete blood count.

- Fasting blood glucose.

- Serum creatinine.

- Chest X-ray and E.C.G. studies of patients having medical history suggesting cardio-respiratory problem.

- All the patient undergoing spinal anaesthesia were explained regarding the procedure and prior consent for the procedure was obtained 


\section{Inclusion criteria-}

- All patients of ASA grade $1 \& 2$.

- All patients of age group between 18 to 60 years

- Patient who were disqualified from the study (Exclusion criteria)

- Patient refusal for the procedure.

- Sensitive to local anaesthetics.

- History of allergic reaction or abnormal response to the drug.

- Patient on anticoagulant therapy.

- Bleeding disorder and disturbed coagulation profile.

- Patients using alpha-2 receptors antagonists, calcium-channelsblockers and angiotensin converting enzyme inhibitors.

- Infection in the site of injection.

- Spinal abnormality like kyphosis, scoliosis, lordosis, previous spine surgery.

- Presence of Co-morbid diseases contraindicating spinal subarachnoid block.

All patients were kept NBM after $10 \mathrm{PM}$ and Tab Alprazolam $0.5 \mathrm{mg}$ was given orally H.S. for completely night sleep. IV line was secured with 18 SWG cannula and infusion of RL was started.

The spinal anaesthesia was administrated in a well equipped O.T. with all emergency and essential drugs.

Spinal block was administrated in sitting position by mid line approach. The patient was asked to sit up on the operating table and the back was moved as close to the edge of the table.

The patient was asked to 'Hunch over' so that the lower back is flexed. The objective of keeping patient in such position was to make the interspaces wide for an essay approach to the subarachnoid space. The position was maintained with the help of assistants.

- Back was prepared with antiseptic solution, in the wards before being shifted to the theatre.

- Surgical scrub was done and sterile gown and gloves were put on.

- A large area of skin (from buttocks to the angle of scapula) was painted with savlon, povidone iodine and then with the spirit and finally dry with the dry gauze.

- Local anaesthesia solution for spinal block and infiltration solution were drawn in separate syringes.

- $1 \mathrm{ml}$ of test drug Dexmedetomidine was drawn in insulin syringe.

- As per the assigned study group $0,10 \mathrm{mcg}$ or $15 \mathrm{mcg}$ of Dexmedetomidine was mixed with local anaesthetic solution for injection in subarachnoid space.

- A sterile towel sheet was placed across the buttocks. The landmarks were identified.

- A widest space was selected for the lumber puncture.

- Skin and deep tissue were infiltrated with $2 \%$ lignocaine.

- Stylet and spinal needle were checked.

- The spinal needle was then directed till the duramater was punctured inL3/L4 interspace identifying the intercreastic line.

- The stylet was removed and free flow of C.S.F. was observed.

- After performing lumber puncture hyperbaric Bupivacaine 0.5\% is a dose of $4 \mathrm{ml}(20 \mathrm{mg})$ combined with or without Dexmedetomidine was administrated according to the assigned study group:

1.Group A- Inj. Bupivacaine- 20mg alone.

2.Group B- Inj. Bupivacaine- 20mg with Dexmedetomidine $10 \mathrm{mcg}$

- The syringe along with the needle was withdrawn; the wound was dressed with sterile gauze socked in Tincture Benzoin.

- A 10 degree head tilt was given to all patients after making them in supine position on table.

All patients were oxygenated by facemask@4L/min.

After subarachnoid injection of drug/ drugs according to the assigned group, patients were observed for-

- Onset time of sensory blocks.

- Height of sensory blocks

- Duration of sensory block

- Onset time of motor block

- Height of motor block

- Duration of motor block

- Duration of post operative analgesia

- Sedation score

- Associated hemodynamic changes

- Complications and side effects
- $\quad$ Throughout surgery patients were monitored continuously on a multi-parameter monitor ECG, NIBP, sPO2 and recorded at 5, 10 , $15,20,25$ and 30 minute and then at every fifteen minutes after the administration of drugs in subarachnoid space until the surgery ends or up till 2 hours which ever come fast.

- Injection Atropine and injection Ephedrine was given intravenously on occurrence of significant Bradycardia or hypotension.

- After the operation was over, the pulse, blood pressure was again recorded and patient was shifted to recovery area.

- After the sensory and motor recovery, the patient was shifted to the ward and observed for time of occurrence of pain and time of administration of rescue analgesic injection Diclofenac sodium by intramuscular route was recorded.

- All the observation recorded in the predefined proforma and readings were subjected to statistical analysis.

- The results were tabulated and presented in the form of table and diagrams.

- Observations recorded were discussed in reference of available literature and were reviewed to arrive at conclusion

\section{RESULTS \& DISCUSSION}

Table No.1 Distribution according to high sensory level achieved in bupivacaine and bupivacaine + dexmedetomidine group

\begin{tabular}{|l|l|l|l|l|}
\hline \multirow{2}{*}{$\begin{array}{l}\text { Highest } \\
\text { Sensory } \\
\text { Level }\end{array}$} & \multicolumn{2}{|l|}{ Bupivacaine Group } & \multicolumn{2}{l|}{$\begin{array}{l}\text { Bupivacaine }+ \\
\text { Dexmedetomidine Group }\end{array}$} \\
\cline { 2 - 5 } & Number & Percentage & Number & Percentage \\
\hline T10 & 6 & 18.2 & 6 & 18.2 \\
\hline T8 & 19 & 57.6 & 12 & 36.4 \\
\hline T6 & 8 & 24.2 & 15 & 45.5 \\
\hline Total & 33 & 100.0 & 33 & 100.0 \\
\hline
\end{tabular}

Pearson Chi-square value $=3.711, d f=2, P$ value $=0.156$, Not Significant

In the bupivacaine group, $6(18.2 \%)$ patients reached T10 level, 19 $(57.6 \%)$ patients reached T8 level and $8(24.2 \%)$ patients reached T6 level.

In the bupivacaine + dexmedetomidine group, $6(18.2 \%)$ patients reached T10 level, $12(36.4 \%)$ patients reached T8 level and 15 $(45.5 \%)$ patients reached $\mathrm{T} 6$ level

The association between the highest sensory level and the groups was found to be statistically not significant $(p>0.05)$, showing that the groups are independent of the highest sensory level reached.

Table No.2 Comparison of mean onset of sensory block between the bupivacaine and bupivacaine + dexmedetomidine group

\begin{tabular}{|l|c|c|c|}
\hline \multicolumn{1}{|c|}{ Group } & Mean \pm SD & 't' value & P value \\
\hline Bupivacaine & $92.45 \pm 14.42$ & $2.131, \mathrm{df}=64$ & 0.037, \\
\cline { 1 - 2 } $\begin{array}{l}\text { Bupivacaine }+ \\
\text { Dexmedetomidine }\end{array}$ & $86.39 \pm 7.67$ & & \\
\hline
\end{tabular}

\section{Unpaired 't' test applied. Pvalue $=0.037$}

The difference of mean onset of sensory block in bupivacaine \& bupivacaine+dexmedetomidine group was found to be statistically significant, showing a rapid onset of sensory block in bupivacaine + dexmedetomidine group.

Table No.3 Comparison of mean onset of motor block between the bupivacaine and bupivacaine + dexmedetomidine group

\begin{tabular}{|l|l|l|l|}
\hline Group & Mean \pm SD & 't' value & P value \\
\cline { 1 - 2 } Bupivacaine & $117.21 \pm 29.11$ & $4.098, \mathrm{df}=64$ & $0.000^{*}$ \\
\cline { 1 - 4 } $\begin{array}{l}\text { Bupivacaine }+ \\
\text { Dexmedetomidine }\end{array}$ & $95.24 \pm 10.08$ & & \\
\hline
\end{tabular}

Unpaired 't' test applied. Pvalue $=0.000$, Significant

Table No.4 Comparison of mean duration of motor block between the bupivacaine and bupivacaine + dexmedetomidine group

\begin{tabular}{|l|l|l|l|}
\hline Group & Mean \pm SD & 't' value & P value \\
\hline $\begin{array}{l}\text { Bupivacaine } \\
\text { Bupivacaine }+ \\
\text { Dexmedetomidine }\end{array}$ & $180.45 \pm 37.58$ & $-3.739, \mathrm{df}=64$ & $0.000^{*}$ \\
\hline
\end{tabular}

Unpaired 't' test applied. Pvalue =0.000, Significant 
The difference between mean duration of motor block between 2 groups was found to be significant, showing a higher mean duration in the bupivacaine+dexmedetomidine group.

Table No.5 Comparison of mean time to first analgesia between the bupivacaine and bupivacaine + dexmedetomidine group

\begin{tabular}{|l|l|l|l|}
\hline Group & Mean \pm SD & 't' value & P value \\
\hline Bupivacaine & $183.45 \pm 37.34$ & $-4.460, \mathrm{df}=64$ & $0.000^{*}$ \\
\cline { 1 - 2 } $\begin{array}{l}\text { Bupivacaine }+ \\
\text { Dexmedetomidine }\end{array}$ & $215.00 \pm 16.03$ & & \\
\hline
\end{tabular}

\section{Unpaired 't' test applied. Pvalue $=0.000$, Significant}

The difference was statistically significant $(\mathrm{p}<0.05)$, showing a higher mean time time to first analgesia requirement in bupivacaine + dexmedetomidine group.

Table No. 6 Comparison of mean sedation score between the bupivacaine and bupivacaine + dexmedetomidine group

\begin{tabular}{|l|l|l|l|}
\hline Group & Mean \pm SD & 't' value & P value \\
\hline Bupivacaine & $0.58 \pm 0.50$ & $-1.728, \mathrm{df}=64$ & 0.089, \\
\hline $\begin{array}{l}\text { Bupivacaine }+ \\
\text { Dexmedetomidine }\end{array}$ & $0.85 \pm 0.76$ & & \\
\hline
\end{tabular}

\section{Unpaired 't' test applied. Pvalue =0.049, Significant}

The difference was statistically significant showing a comparable mean sedation score in both the groups.

Table No.7 Comparison of mean MAP at different time intervals in the bupivacaine group

\begin{tabular}{|c|c|c|c|c|}
\hline \multirow[t]{2}{*}{ MAP } & \multicolumn{2}{|c|}{$\begin{array}{l}\text { Bupivacaine Group } \\
(\mathrm{n}=33)\end{array}$} & \multirow[t]{2}{*}{ 't' value } & \multirow[t]{2}{*}{ P value } \\
\hline & No. & Mean \pm SD & & \\
\hline Baseline & 33 & $86.88 \pm 8.77$ & & \\
\hline At $5 \mathrm{~min}$ & 33 & $95.36 \pm 6.53$ & $-4.234, \mathrm{df}=32$ & $0.000 *$ \\
\hline At $10 \mathrm{~min}$ & 33 & $76.27 \pm 15.09$ & $3.304, \mathrm{df}=32$ & $0.002 *$ \\
\hline At $15 \mathrm{~min}$ & 33 & $77.42 \pm 5.31$ & $4.813, \mathrm{df}=32$ & $0.000 *$ \\
\hline At $20 \mathrm{~min}$ & 33 & $78.12 \pm 6.00$ & $4.948, \mathrm{df}=32$ & $0.000 *$ \\
\hline At $25 \mathrm{~min}$ & 33 & $80.94 \pm 5.31$ & $3.151, \mathrm{df}=32$ & $0.004 *$ \\
\hline At $30 \mathrm{~min}$ & 33 & $81.27 \pm 5.45$ & $3.307, \mathrm{df}=32$ & $0.002 *$ \\
\hline At $30-60 \mathrm{~min}$ & 33 & $81.97 \pm 6.63$ & $2.403, \mathrm{df}=32$ & $0.022 *$ \\
\hline At $60-90 \mathrm{~min}$ & 33 & $81.42 \pm 5.26$ & & \\
\hline At $90-120 \mathrm{~min}$ & 28 & $82.43 \pm 6.56$ & $2.086, \mathrm{df}=27$ & $0.047 *$ \\
\hline At $120-150 \mathrm{~min}$ & 9 & $79.00 \pm 3.74$ & $1.797, \mathrm{df}=8$ & $0.110, \mathrm{NS}$ \\
\hline At $150-180 \mathrm{~min}$ & 0 & $0.00 \pm 0.00$ & - & - \\
\hline
\end{tabular}

Paired ' $t$ ' test applied. $P$ value $<0.05$ was taken as statistically significant.

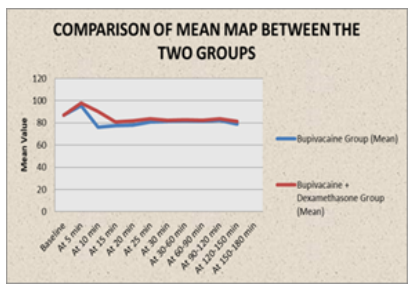

In the bupivacaine group, there was an increase at 5 minutes, then a fall at 10 minutes, then remained stable till 20 minutes, then a slight increase at 25 minutes till 30-60 minutes, then a slight fall at 60-90 minutes, then a slight increase at 90-120 minutes, then a slight fall at 120-150 minutes.

In the bupivacaine + dexmedetomidine group, there was an increase at 5 minutes, then a fall at 10 minutes, which continued till 15 minutes, then a slight increase at 20 minutes which continued till 25 minutes, then a slight fall at 30 minutes, which remained stable till 90-120 minutes and then a slight fall at 120-150 minutes.

The mean MAP was statistically higher in the bupivacaine + dexmedetomidine group in comparison to the bupivacaine group at 15 minutes, 20 minutes, 25 minutes $(\mathrm{p}<0.05)$, while it was comparable at all the other time intervals $(\mathrm{p}>0.05)$.

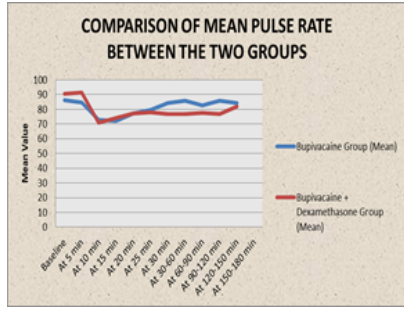

Table No.9 Distribution according to adverse events in bupivacaine and bupivacaine + dexmedetomidine group

\begin{tabular}{|l|l|l|l|l|}
\hline \multirow{2}{*}{$\begin{array}{l}\text { Adverse } \\
\text { Events }\end{array}$} & \multicolumn{2}{|l|}{ Bupivacaine Group } & \multicolumn{2}{|l|}{$\begin{array}{l}\text { Bupivacaine + } \\
\text { Dexmedetomidine Group }\end{array}$} \\
\cline { 2 - 5 } & Number & \% & Number & \% \\
\hline None & 14 & 42.4 & 22 & 66.7 \\
\hline Bradycardia & 7 & 21.2 & 7 & 21.2 \\
\hline Hypotension & 9 & 27.3 & 4 & 12.1 \\
\hline Shivering & 2 & 6.1 & 0 & 0.0 \\
\hline Vomiting & 3 & 9.1 & 2 & 6.1 \\
\hline
\end{tabular}

\section{CONCLUSION}

In our study we found that Dexmedetomidine $(10 \mathrm{mcg})$, when used as an adjunct to $20 \mathrm{mg}(4 \mathrm{ml}), 0.5 \%$ hyperbaric bupivacaine prolongs the duration of effective analgesia in the immediate postoperative period without any significant hemodynamic instability. The mild sedation resulting from intrathecal dexmedetomidine may be beneficial in procedures.

\section{REFERENCES}

[1] Kanazi GE, Aouad Mt, KJabbour-Khoury SI et al: Effect of low dose dexmedetomidine or clonidine on the characteristics of spinal bupivacaine block. Act a Anaesthesiol Scand 2006;50:222-7

[2] Hala EEA, Mohamed SA, Hend Y. Dose related prolongation of hyperbaric bupivacaine spinal anaesthesia by dexmedetomidine. Ain Shams J Anaesthesiology 2011:4:83-95

[3] Kim JE, Kim NY, Lee HS, Kil HK. Effects of intrathecal dexmedetomidine on low dose bupivacaine spinal anaesthesia in elderly patients undergoing transurethral prostectomy. Bio Pharm Bul 2013;36;959-965.

[4] Mahendru V, Tewari A, Katyal S et al. A Comparison of intrathecal dexmedetomidine, clonidine, \& fentanyl as adjuvants to hyperbaric bupivacaine for lower limb surgery: A double blind controlled study. J Anaesthesiol Clin Phrmacol 2013;29:496-502

[5] Soumya samal et al: Intrathecal buterphenol or intrathecal dexmedetomidine for pos operative analgesia a comparative study: healt agenda, vol 2. Issue 1. Jan 2014

[6] Dexmedetomidine in anaesthesia practice: a wonder drug? IJA aug 2014 by S K Harsoor

[7] Cum K, Raghvesta Rao R S, Kavya M, Aarhi J, Rani D D, Nethra s s. Comprative study of 2 doses of intrathecal dexmedetomidine as adjunct with low dose hyperbaric bupivacaine in ambulatory perianal surgeries. A prospective randomized controlled study. Indian J Anaesth 2015;59:648-52

[8] El-Attar A, Aleen MA, Beltagy R, Ahmed W. A comparative study of intrathecal dexmedetomidine and fentanyl as additives to bupivacaine. Res Opin Anesth Intensive care 2015;1:43-9

[9] Kurhekar P, Kumar SM, Sampath D. Comparative evaluation of intrathecal morphine and intrathecal dexmedetomidine in patients undergoing gynecological surgeries under spinal anaesthesia. A prospective randomized double blind study. Indian J anaestg 2016:60:382-7 